\title{
Stent treatment for coarctation of the aorta: intermediate term follow up and technical considerations
}

\author{
B D Thanopoulos, L Hadjinikolaou, G N Konstadopoulou, G S Tsaousis, F Triposkiadis, \\ P Spirou
}

\begin{abstract}
Objective-To report the initial and intermediate term results of stent implantation in children with coarctation of the aorta.

Patients and design-17 patients with coarctation of the aorta underwent stent implantation (median age 11 years, range 0.4-15 years); six were treated for isolated coarctation, nine for recurrent coarctation (five after surgical repair and four after balloon dilatation), and two for complex long segment coarctation.

Interventions-The procedure was guided by a second catheter placed transseptally in the left ventricle or the aorta proximal to the coarctation site, for angiographic and haemodynamic monitoring during the procedure. Twenty two stents were implanted in 17 patients. One of the patients with long segment coarctation received four stents and the other three. Palmaz 4014 stents were placed in 11 patients, Palmaz 308 in five, and Palmaz 154 in one.

Results-Immediately after stent implantation the peak systolic gradient (mean (SD)) fell from $50.0(24.5)$ to $2.1(2.4) \mathrm{mm} \mathrm{Hg}(\mathrm{p}<0.05)$. The diameter of the stenotic lesion increased from $5.1(1.5) \mathrm{mm}$ to $13.9(2.4) \mathrm{mm}(\mathrm{p}<0.05)$. There were no deaths or procedure related complications. At a median follow up of 33 months, no cases of recoarctation were identified, either clinically $(0 / 17 ; 0 \%, 95 \%$ confidence interval (CI) $0 \%$ to $19 \%)$ or angiographically $(0 / 13 ; 0 \%, 95 \%$ CI $0 \%$ to $25 \%$ ).

Conclusions-Stent implantation for the treatment of coarctation of the aorta appears to have very low morbidity and mortality, and reasonable intermediate term results. Long term freedom from recoarctation using this method remains to be determined in comparison with simple balloon dilatation.

(Heart 2000;84:65-70)
\end{abstract}

Keywords: aortic coarctation; blood vessel prostheses; stents

Stenting has been gaining acceptance in the treatment of isolated coarctation of the aorta. Its theoretical advantage over simple balloon dilatation is a potentially lower incidence of recoarctation. However, to date there is limited information on the incidence of intermediate and long term recoarctation following stenting. Ebeid and colleagues reported that one of nine patients treated with stents developed significant recoarctation at a mean of 18 months' follow up. ${ }^{1}$ Suarez de Lezo and colleagues found that three of 30 patients suffered mild stenosis at a mean of two years of angiographic follow up, and a further five developed non-significant lumen reduction owing to mild intimal thickening. ${ }^{2}$ On the other hand, a significant number of patients develop recoarctation following simple balloon dilatation for native or postoperative coarctation. ${ }^{3-6}$

We report our experience, technique, and intermediate term clinical and angiographic follow up results in patients undergoing stent treatment for isolated coarctation of the aorta.

\section{Methods}

STUDY POPULATION

The study was approved by the hospital ethics committee, and written informed consent was obtained from the parents or guardians of all the patients. From November 1992 to January 1999, 17 patients with coarctation of the aorta underwent stent implantation at the Aghia Sophia Children's Hospital in Athens. There were 11 girls and six boys, median age 11 years (range $0.4-15$ years) and median body weight $36 \mathrm{~kg}$ (range $6-55 \mathrm{~kg}$ ). Nine patients underwent stent implantation for recurrent coarctation. Of these, three had undergone a single surgical repair, one had undergone two previous surgical repairs and a balloon dilatation, and four had undergone balloon dilatation only. Eight patients underwent stent implantation as the method of first choice. Two of these had a complex long segment coarctation and the surgical risk was considered high; in the remaining six the parents refused consent for surgery. Patients with significant hypoplasia of the distal aortic arch or aortic isthmus proximal to the coarctation were excluded from the study. Hypoplasia was defined as a ratio of the diameter of aortic arch or isthmus to the diameter of descending aorta at the level of diaphragm of less than 0.6 .

\section{PROCEDURE}

Percutaneous cardiac catheterisation was routinely performed from the femoral or inguinal region. Ten procedures were done with local anaesthesia and sedation, while the remaining seven were done under general anaesthesia. Intravenous heparin $(100 \mathrm{U} / \mathrm{kg})$ was given immediately after arterial cannulation. A 

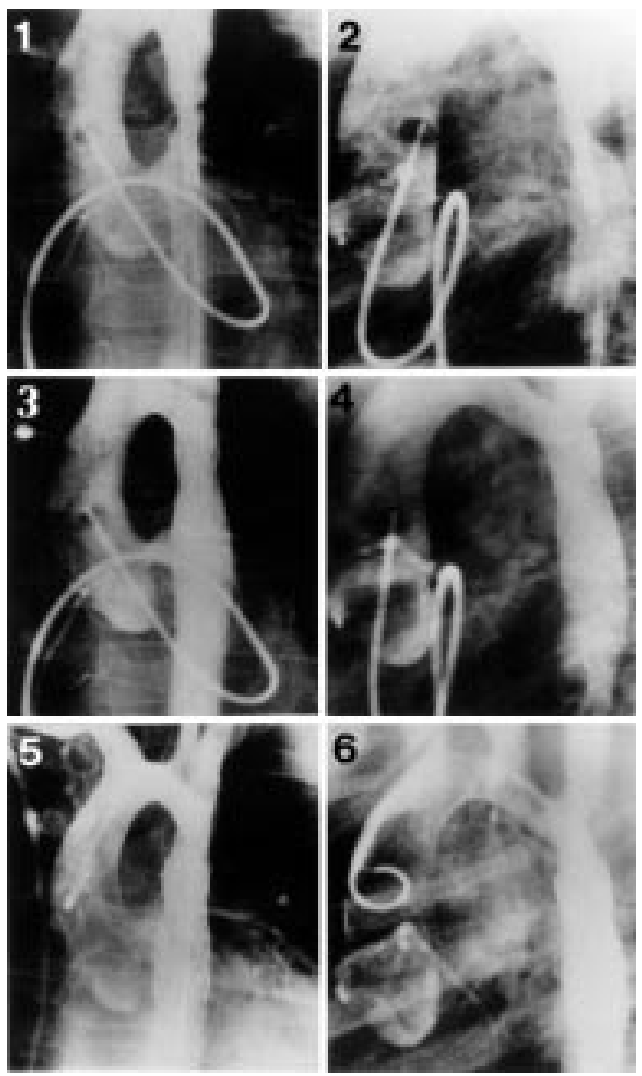

Figure 1 Antegrade ascending aortograms in the anteroposterior (1) and lateral (2) projections, showing the position of a stent across the coarctation before expansion. Repeat anteroposterior (3) and lateral (4) aortogram projections showed an aortic diameter of $13 \mathrm{~mm}$ at the stented segment and good stent position. Retrograde anteroposterior (5) and lateral (6) ascending aortogram projections 36 months later showed no evidence of restenosi and good stent position without fracture or displacement (patient 2, tables 1 and 2).
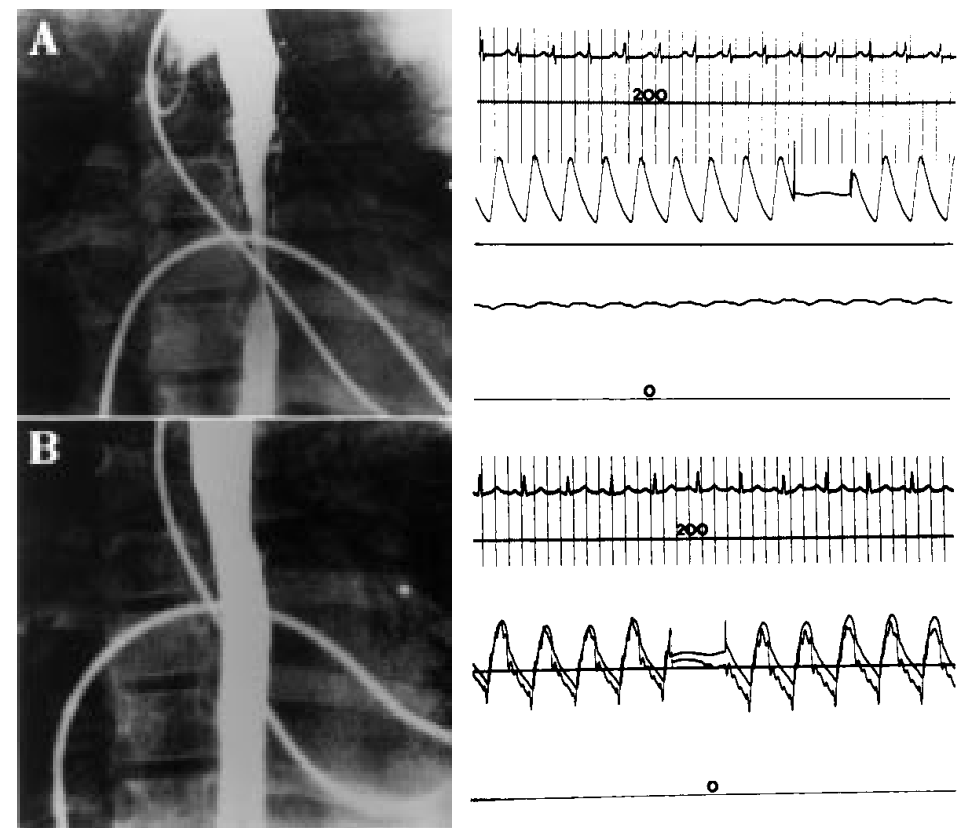

Figure 2 Antegrade ascending aortograms (left panels) and simultaneous ascending and descending aortic pressure tracings (right panels) obtained from a patient with long segment coarctation before $(A)$ and immediately after (B) multiple stent implantation. An impressive increase in coarctation diameter and elimination of the pressure gradient across the coarctation is seen after deployment of the stents (patient 7, tables 1 and 2). pigtail angiographic catheter (Cordis, Miami, Florida, USA) was advanced into the ascending aorta and systolic pressure differences across the area of coarctation were recorded. Subsequently biplane aortograms were obtained and multiple aortic diameter measurements carried out on the lateral view at the following sites:

- distal aortic arch directly proximal to the left subclavian artery;

- proximal aortic isthmus just distal to the left subclavian artery;

- at the level of the coarctation;

- at the level of the diaphragm.

Correction for magnification was performed using the known diameter of the catheter or the distance between the electrodes of a pacing catheter (Elecath Co, Rahway, New Jersey, USA). The diameters of both the distal aortic arch and the isthmus were indexed to that of the descending aorta at the level of diaphragm. A second 6 French to 8 French balloon tipped angiographic catheter (Arrow International, Reading, Pennsylvania, USA) was introduced transseptally into the left ventricle or the ascending aorta proximal to the coarctation site to provide angiographic and haemodynamic guidance of the procedure (antegrade angiographic and haemodynamic guidance technique, $\mathrm{AAHG}$ ) (figs 1,2 , and 3 ).

A long transeptal sheath, 6 French to 12 French in size, and a dilator set (Cook Europe, Bjaevenskov, Denmark) were advanced through the femoral artery and placed across the coarctation. The dilator was removed, leaving the guide wire and the sheath across the stenotic lesion. A Palmaz stent (P154, $1.5 \mathrm{~cm}$ long and $2.4 \mathrm{~mm}$ nominal diameter, P308, $3 \mathrm{~cm}$ long and $3.4 \mathrm{~mm}$ nominal diameter, or P4014, $4 \mathrm{~cm}$ long and $4.6 \mathrm{~mm}$ nominal diameter; Johnson and Johnson International Systems, Warren, New Jersey, USA) was securely placed on an angioplasty balloon $(6,12,15$, or $18 \mathrm{~mm}$ PEMT, Meditech, Watertown, Massachusetts, USA). The diameter of the balloon was equal to or $1 \mathrm{~mm}$ greater than the diameter of the proximal aortic isthmus, but not greater than the diameter of the descending aorta at the level of the diaphragm. The balloon was inflated to pressures ranging from 3-12 atm, as recommended by the manufacturer. In nine patients further dilatation with the same or a larger balloon (up to $20 \mathrm{~mm}$ ) was performed until satisfactory relief of the stenotic waist was achieved. After the procedure, repeat aortography and pressure measurements distal and proximal to the stented segment were obtained (fig 2).

All patients received aspirin 3-5 mg/kg daily for six months. They were followed up clinically at one and three months after the procedure and then every six months. Follow up included arm and leg blood pressure measurements and chest radiography. Blood pressure was measured in the right arm and in the leg not used for the angioplasty procedure. Median clinical follow up time was 33 months (range 10-82 months). Follow up angiographic studies were performed in 13 of 17 patients. Median angiographic follow up time was 30 

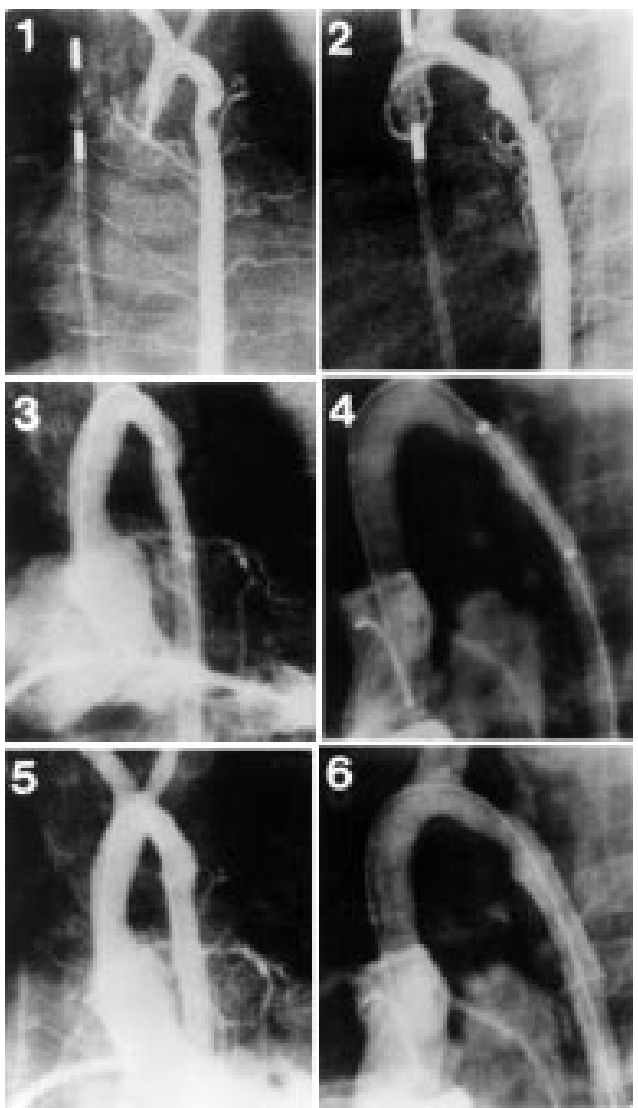

Figure 3 Ascending aortograms in the anteroposterior (1) and lateral (2) projections, revealing a discrete recoarctation in a 4 month old infant after a left subclavian flap operation. Left ventriculography in the anteroposterior (3) and lateral (4) projections show the position of a stent across the coarctation before expansion. Left

ventriculography in the anteroposterior (5) and lateral (6) projections show a reasonable increase in coarctation diameter following stent placement (patient 1, tables 1 and 2).

months (range 18-72 months). A satisfactory late result was defined as the absence of restenosis on follow up catheterisation, as well as a residual pressure gradient less than $20 \mathrm{~mm} \mathrm{Hg}$, measured either on repeat catheterisation or by cuff sphygmomanometry.

Table 1 Demographic data

\begin{tabular}{|c|c|c|c|c|}
\hline $\begin{array}{l}\text { Patient } \\
\text { No/sex }\end{array}$ & $\begin{array}{l}\text { Age (years)/ } \\
\text { weight (kg) }\end{array}$ & Diagnosis & Previous surgery & $\begin{array}{l}\text { Previous balloon } \\
\text { dilatation }\end{array}$ \\
\hline $1 / M$ & $0.4 / 6$ & $\begin{array}{l}\text { CoA, Mild SVAS, } \\
\text { Williams syndrome }\end{array}$ & $\begin{array}{l}\text { Subclavian turndown, } \\
\text { end to end anastomosis }\end{array}$ & + \\
\hline $2 / M$ & $7.5 / 28$ & $\mathrm{CoA}$ & - & + \\
\hline $3 / \mathrm{M}$ & $15 / 46$ & $\mathrm{CoA}$ & End to end anastomosis & - \\
\hline $4 / \mathrm{F}$ & $12 / 39$ & CoA & End to end anastomosis & - \\
\hline $5 / \mathrm{F}$ & $9 / 34$ & $\begin{array}{l}\text { CoA, Turner } \\
\text { syndrome }\end{array}$ & - & + \\
\hline $6 / M$ & $14 / 42$ & $\mathrm{CoA}$ & End to end anastomosis & - \\
\hline $7 / \mathrm{M}$ & $13 / 55$ & Long segment, CoA & - & - \\
\hline $8 / \mathrm{F}$ & $12 / 37$ & $\begin{array}{l}\text { Long segment, CoA, } \\
\text { absent LPA }\end{array}$ & - & - \\
\hline 9/M & $14 / 44$ & $\mathrm{CoA}$ & - & + \\
\hline $10 / \mathrm{F}$ & $10 / 35$ & $\begin{array}{l}\text { CoA, Turner } \\
\text { syndrome }\end{array}$ & - & + \\
\hline $11 / \mathrm{M}$ & $15 / 48$ & CoA & End to end anastomosis & + \\
\hline $12 / \mathrm{F}$ & $13 / 37$ & $\mathrm{CoA}$ & - & - \\
\hline $13 / \mathrm{F}$ & $10 / 33$ & $\mathrm{CoA}$ & - & - \\
\hline $14 / \mathrm{F}$ & $9 / 34$ & $\mathrm{CoA}$ & - & - \\
\hline $15 / F$ & $8 / 31$ & CoA & - & - \\
\hline $16 / \mathrm{F}$ & $16 / 65$ & $\mathrm{CoA}$ & - & - \\
\hline $17 / \mathrm{F}$ & $15 / 55$ & CoA & - & - \\
\hline
\end{tabular}

CoA, coarctation of the aorta; LPA, left pulmonary artery; SVAS, supravalvar aortic stenosis.
STATISTICAL ANALYSIS

Data were analysed with the Statgraphics statistical program (version 6.0, Manugistics). The Kolmogorov-Smirnof test was used to compare the distribution of each variable with the normal distribution. Pre- and post-stent implantation data were compared using the paired Wilcoxon test. Results are expressed as mean (SD), or median with minimum and maximum values if the distribution was not normal.

\section{Results}

Demographic and clinical data on the patients are presented in table 1 . In seven patients the diagnosis of aortic coarctation followed the finding of systemic hypertension on routine clinical examination. In the remainder the suspicion of coarctation was raised at routine examination and confirmed by echocardiography and Doppler evaluation. Two patients suffered from Turner syndrome and one from Williams syndrome. No patient suffered from any other associated cardiac abnormality. Two patients had long segment stenosis. The youngest patient who underwent stent implantation was an infant with Williams syndrome who had recurrent coarctation of the aorta following two previous attempts for surgical repair, a subclavian flap and an end to end anastomosis, and a balloon dilatation.

The catheterisation and follow up data are given in table 2. Stent implantation was decided on the basis of angiographic evidence of significant coarctation, and all procedures were performed by a single operator (BT). Twenty two stents were implanted in 17 patients. Four and three stents were placed in patients 7 and 8, respectively, because of long segment coarctation. Palmaz 4014 stents were placed in 11 patients, Palmaz 308 in five, and Palmaz 154 in one. The latter was used in the 4 month old infant (fig 3).

The diameter of the stenotic lesion (mean (SD)) increased from 5.1 (1.5) $\mathrm{mm}$ to 13.9 $(2.4) \mathrm{mm}(\mathrm{p}<0.05)$. This represents a 190 $(97) \%$ post-stent implantation increase in diameter. The peak systolic gradient across the coarctation of the aorta was reduced from 50.0 (24.5) to 2.1 (2.4) $\mathrm{mm} \mathrm{Hg}(\mathrm{p}<0.05)$. Mild proximal stent migration without adverse effects occurred in one patient during an attempt at further dilatation. All patients were discharged 48 hours after the procedure.

At follow up, 15 of the 17 patients $(88 \%$, $95 \%$ confidence interval (CI) $64 \%$ to $99 \%$ ) were normotensive, with a systolic arterial pressure less than the 95th centile for age. Two patients (patients 1 and 7) were treated with low doses of propranolol because of mild resting hypertension. The systolic blood pressure difference between arms and legs, measured by cuff, was $6.7 \quad$ (4.6) $\mathrm{mm} \mathrm{Hg}$ (range $0-15 \mathrm{~mm} \mathrm{Hg}$ ) at a median of 33 months of follow up (range 10-82 months). On chest radiographs, all stents were in a good position, with no fracture or significant dislodgement. In patient 7, who had multiple Palmaz 308 stents because of long segment stenosis, there was a degree of kinking and proximal dilatation of the 
Table 2 Data before and after stent implantation

\begin{tabular}{|c|c|c|c|c|c|c|c|c|c|c|}
\hline \multicolumn{3}{|c|}{ Before stent implantation } & \multicolumn{3}{|c|}{ After stent implantation } & \multicolumn{3}{|c|}{ Follow up catheterisation } & \multicolumn{2}{|l|}{ Follow up } \\
\hline $\begin{array}{l}\text { Patient } \\
\text { number }\end{array}$ & $\begin{array}{l}\text { CoA size } \\
(\mathrm{mm})\end{array}$ & $\begin{array}{l}S P G \\
(m m \mathrm{Hg})\end{array}$ & $\begin{array}{l}\text { CoA size } \\
(\mathrm{mm})\end{array}$ & Stent type & $\begin{array}{l}S P G \\
(m m \mathrm{Hg})\end{array}$ & $\begin{array}{l}\text { Time } \\
\text { (months) }\end{array}$ & $\begin{array}{l}\text { CoA size } \\
(\mathrm{mm})\end{array}$ & $\begin{array}{l}S P G \\
(m m \mathrm{Hg})\end{array}$ & $\begin{array}{l}\text { SBPG } \\
\text { (arm/leg, } \mathrm{mm} \mathrm{Hg} \text { ) }\end{array}$ & $\begin{array}{l}\text { Period } \\
\text { (months) }\end{array}$ \\
\hline 1 & 2.5 & 45 & 6 & P 154 & 5 & - & - & - & 15 & 10 \\
\hline 2 & 5 & 40 & 13 & P 4014 & 4 & 36 & 13 & 6 & 10 & 35 \\
\hline 3 & 7 & 25 & 17 & P 4014 & 0 & 18 & 16 & 0 & 5 & 39 \\
\hline 4 & 6 & 35 & 15 & P 4014 & 2 & 30 & 15 & 4 & 5 & 40 \\
\hline 5 & 5 & 40 & 14 & P 4014 & 0 & 30 & 14 & 6 & 8 & 28 \\
\hline 6 & 7 & 25 & 15 & P 4014 & 0 & 18 & 15 & 5 & 7 & 34 \\
\hline 7 & 5 & 65 & 13 & P 308 & 5 & 72 & 14 & 10 & 15 & 82 \\
\hline 8 & 2.5 & 120 & 12 & P 308 & 5 & - & - & - & 8 & 11 \\
\hline 9 & 4 & 80 & 13 & P 308 & 5 & 30 & 13 & 6 & 12 & 49 \\
\hline 10 & 6 & 30 & 14 & P 4014 & 5 & 18 & 13 & 4 & 7 & 33 \\
\hline 11 & 6 & 35 & 16 & P 4014 & 0 & 24 & 15 & 0 & 0 & 31 \\
\hline 12 & 7 & 30 & 15 & P 4014 & 0 & 36 & 15 & 0 & 5 & 35 \\
\hline 13 & 5 & 45 & 14 & P 4014 & 0 & - & - & - & 5 & 13 \\
\hline 14 & 4 & 70 & 14 & P 308 & 5 & 36 & 13 & 6 & 8 & 45 \\
\hline 15 & 5 & 65 & 16 & P 4014 & 0 & 42 & 16 & 0 & 4 & 32 \\
\hline 16 & 2.5 & 60 & 15 & P 308 & 0 & - & - & - & 0 & 10 \\
\hline 17 & 5 & 40 & 15 & P 4014 & 0 & 24 & 15 & 0 & 0 & 29 \\
\hline Mean & 5.1 & 50 & 13.9 & & 2.1 & $30^{\star}$ & 14.4 & 3.6 & 6.7 & $33^{\star}$ \\
\hline $\begin{array}{l}\text { SD or } \\
\text { (range) }\end{array}$ & 1.5 & 24.5 & 2.4 & & 2.4 & (18 to 72$)$ & 1.2 & 3.3 & 4.6 & (10 to 82$)$ \\
\hline
\end{tabular}

Statistical analysis was performed comparing the coarctation diameter and systolic pressure gradient before and after implantation.

${ }^{\star}$ Median value.

BP, blood pressure; CoA, coarctation of the aorta; P, Palmaz; SBPG, systolic blood pressure gradient; SPG, peak systolic gradient.

aorta in the vicinity of the superior border of the stented segment immediately after the procedure. The follow up angiogram showed an aortic diameter of $14 \mathrm{~mm}$ at the coarctation site, and there was a $10 \mathrm{~mm} \mathrm{Hg}$ peak systolic pressure gradient across the stented area. There was mild discontinuity of the proximal and distal stents in relation to the central two overlapping stents (fig 4).

The peak systolic pressure gradient across the stented area was 3.6 (3.3) $\mathrm{mm} \mathrm{Hg}$ (range

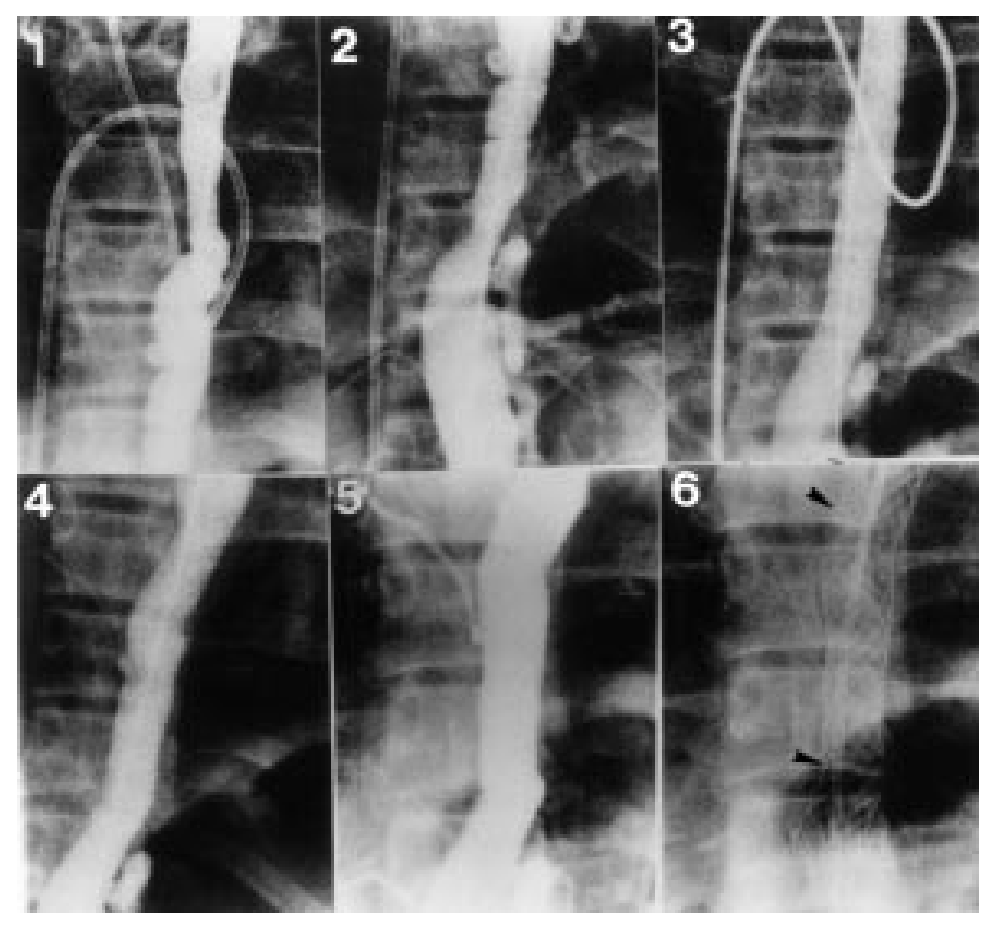

Figure 4 Descending aortograms showing the treatment of a long segment coarctation of aorta with multiple stents. Picture 1 shows the upper part of the coarctation and picture 2 the lower part. Picture 3 shows the descending aorta immediately after placement of four stents. Pictures 4 and 5 show follow up aortograms one and six years after the procedure, respectively. There was no significant change in the aortic diameter at the stented area. Picture 6 shows a plain film radiograph six years after the procedure. Notice the mild stent dislodgement at the junctions between the first and second, as well as the third and fourth stents (arrowheads) (patient 7, tables 1 and 2).
$0-10 \mathrm{~mm} \mathrm{Hg}$ ) and the mean aortic diameter at the coarctation site (contrast jet through the centre of the stent) was $14.4(1.2) \mathrm{mm}$ (range $13-16 \mathrm{~mm}$ ) at a median angiographic follow up time of 30 months (range 18-72 months). No patient developed angiographically significant restenosis. Mild intimal hyperplasia within the stent was observed in five patients $(29 \%$, $95 \%$ CI $0.3 \%$ to $56 \%$ ).

There were no early or late deaths, or any evidence of early or late aneurysm formation, endocarditis, thromboembolism or any other complication related to stent implantation throughout the follow up period. No patient had either absent or low volume distal pulses immediately after the procedure or at follow up.

\section{Discussion}

To date, clinical reports on stent implantation for isolated coarctation of the aorta have been sporadic. Since 1991, 77 cases have been reported from seven centres ${ }^{12}$ 7-17 and seven of these were case reports. There is only one report giving intermediate term angiographic follow up data. ${ }^{2}$ In the present report, 13 of the 17 patients had angiographic studies at a median of 30 months of follow up (range 18-72 months).

The most common criteria for treating coarctation of the aorta with stents have been previous surgical repair, high surgical risk, refusal of consent for surgical intervention, and unfavourable anatomy for balloon angioplasty $^{127-17}$; young age, a hypoplastic isthmus, and a distal aortic arch represent major drawbacks for balloon dilatation and probably also for stent implantation. ${ }^{18}$ In the present study, the indications for stent implantation were similar to those in previous studies, including long segment coarctation. Two patients with long segment stenosis were treated with multiple stent implantation in the descending aorta. In the first patient, a $160 \%$ increase in the smallest aortic diameter was 
obtained after stent implantation, and this remained essentially unchanged at the 72 month follow up. In the second patient, a 380\% increase in the smallest aortic diameter was observed immediately after stent implantation. Although this patient did not have late angiographic studies, the arm-leg systolic pressure difference was $8 \mathrm{~mm} \mathrm{Hg}$ at 11 months after the procedure. In our series, the average age of the 16 patients after infancy was 12.3 years (range $7.5-15$ years); there was only one infant, aged 4 months, in whom stent implantation was unavoidable because of recurrent coarctation after two previous attempts at surgical repair, as well as a balloon dilatation. The arm-leg systolic pressure difference in this infant was $15 \mathrm{~mm} \mathrm{Hg}$ at 10 months after the procedure.

\section{COMPARISON WITH PREVIOUS STUDIES}

Our stent implantation technique is slightly different from those used in other centres, ${ }^{12}$ as it includes a second catheter introduced transseptally into the left ventricle or aorta proximal to the coarctation site (AAHG technique). This catheter is used for the following:

- performance of aortography before dilating the coarctation, to ensure ideal positioning of the stent;

- assessment of the result of angioplasty by dye injection immediately after stent placement;

- monitoring systemic blood pressure and arterial blood gases during balloon dilatation;

- estimating the post-stent implantation pressure gradient without the need to cross the lesion, using simultaneous pressure recordings from the balloon tipped and Pigtail catheters, or the side arm of the arterial sheath.

We firmly believe that the above advantages overweigh the potential risks related to the atrial septal puncture, and indeed there were no procedure related complications.

In most but not all studies, balloon dilatation has been performed immediately before stent implantation, and when haemodynamic assessment shows persistence of an unacceptable gradient despite adequate dilatation, the decision is made to implant a stent. ${ }^{127-17}$ Stent placement as the initial procedure has previously been undertaken in certain cases at the physician's discretion; in the present study it was performed as the initial procedure in all cases. In our experience, balloon dilatation before stent implantation is not necessary and may expose the patient to the additional risk of aortic rupture. ${ }^{18} 19$

Apart from the 4 month old infant who received a Palmaz 154 stent, the remaining patients received either Palmaz 308 or Palmaz 4014 stents. To our knowledge this is the first use of the 4014 stent in the treatment of coarctation of the aorta, and we think it may be more appropriate than the 308 stent. It has a larger expanded diameter (14-25 mm versus $8-12 \mathrm{~mm}$ ) and it is also longer at maximum expansion $(30.6 \mathrm{~mm}$ at $25 \mathrm{~mm}$ expanded diameter versus $26.2 \mathrm{~mm}$ at $12 \mathrm{~mm}$ expanded diameter). In the present study, only one of the five Palmaz 308 stents was expanded up to the safe $12 \mathrm{~mm}$ maximum expanded diameter, while the remainder were expanded to diam- eters ranging from $13-15 \mathrm{~mm}$. On the other hand, the expanded diameter of Palmaz 4014 stents ranged from $13-17 \mathrm{~mm}$, far less than their $25 \mathrm{~mm}$ maximum expanded diameter. The greater length of the 4014 stent may be particularly useful in cases of long segment stenosis, where fewer stents may be needed. Also, their larger maximum expanded diameter may allow safe additional expansion in the future if necessary. Unfortunately, in the two cases with long segment stenosis in the present study, 4014 stents were not available and were therefore not used.

Mortality following stent implantation for coarctation has been zero in all previous studies, ${ }^{127-17}$ as well as in the present study. Potential stent related complications include incomplete stent expansion, stent fracture, distal migration, and thromboembolic episodes. More unusual complications include aortic disruption and femoral artery damage. Late aneurysm formation requiring intervention has ranged from $0-7 \%$ in previous studies. ${ }^{121113}$ None of these complications was encountered in the present study. The low morbidity in our series might reflect the high accuracy of stent placement achieved by the AAHG technique. Stent reexpansion was not required in any case.

\section{STUDY LIMITATIONS}

Recoarctation after simple balloon dilatation ranges from 9-80\%. ${ }^{3-6}$ In previous studies, recoarctation after stent implantation has been approximately $10 \%$ at intermediate follow up. ${ }^{12}$ In the present study there were no cases of recoarctation. This may reflect any or all of the following: exclusion from the study of patients with significant hypoplasia of the distal arch or aortic isthmus; the higher accuracy of procedures done using the AAHG technique; or the performance of the procedure by a single experienced operator. With the data presently available it is difficult to determine whether stent implantation provides superior intermediate and long term patency than the simple balloon dilatation. The inability to compare results between conventional surgical procedures, balloon dilatation, and balloon expandable stents results from the lack of a prospective randomised study. This is the major limitation of the present study and of all previous studies. Finally, owing to limited clinical information concerning stent redilatation, ${ }^{1} 1315$ the currently available stents should be implanted in older children (older than 6 years) in whom the normal aortic diameter range overlaps that of young adults. ${ }^{20}$

\section{CONCLUSIONS}

Our results indicate that stent implantation may be an effective and safe treatment in selected children with coarctation of the aorta. The long term freedom from recoarctation with this method compared with simple balloon dilatation remains to be elucidated. Antegrade angiographic and haemodynamic guidance may be associated with reduced procedural morbidity and improved results.

Presented in part at the XXIst Congress of the European Society of Cardiology in Barcelona, Spain, August 1999. 
1 Ebeid MR, Pietro LR, Latson LA. Use of balloon expandable stents for coarctation of the aorta: initial results and intermediate-term follow-up. $\mathcal{F} \mathrm{Am}$ Coll Cardio

2 Suarez de Lezo J, Pan M, Romero M, et al. Immediate and follow-up findings after stent treatment for severe coarctation of the aorta. Am $\mathcal{F}$ Cardiol 1999;83:400-6.

3 Fletcher SE, Nihill MR, Grifka RG, et al. Balloon angioplasty of native coarctation of the aorta: midterm follow-up and prognostic factors. $\mathcal{F} \mathrm{Am}$ Coll Cardiol 1995;25:730-4

4 Mendelsohn AM, Lloyd TR, Crowley DC, et al. Late follow-up of balloon angioplasty in children with a native coarctation of the aorta. Am $\mathcal{F}$ Cardiol 1994;74:696-700.

5 Rao PS. Balloon angioplasty for aortic re-coarctation following previous surgery. In: Rao PS, ed. Transcatheter therapy in pediatric cardiology. New York: Wiley-Liss, 1993:206-8.

6 Hellenbrand WE, Allen HD, Golinko RJ, et al. Balloon angioplasty for aortic coarctation: results of the valvuloplasty and angioplasty of congenital anomalies registry. $\mathrm{Am}$ plasty and angioplasty of

7 O'Laughlin MP, Perry SB, Lock JE, et al. Use of endovascular stent in congenital heart disease. Circulation 1991;83 1923-39.

8 Redington AN, Hayes AM, Ho SY. Transcatheter stent implantation to treat aortic coarctation in infancy. $\mathrm{Br}$ Heart F 1993;69:80-2

9 Redington AN, Weil J, Somerville J. Self expanding stents in congenital heart disease. Br Heart $\mathcal{f}$ 1994;72:378-83.

10 Suarez de Lezo J, Pan M, Romero M, et al. Balloon expandable stent repair of severe coarctation of aorta. Am Heart $\mathcal{f}$ 1995;129:1002-8.

11 Diethrich EB, Heuser RR, Cardenas JR, et al. Endovascular techniques in adult aortic coarctation: the use of stents for native and recurrent coarctation repair. 7 Endovasc Surg 1995;2:183-8.
12 Ing FF, Goldberg B, Siegel DH, et al. Arterial stents in the management of neurofibromatosis and renovascular hypertension in a pediatric patient: case report of a new treatment modality. Cardiovasc Intervent Radiol 1995;18: 414-18.

13 Bulbul ZR, Bruckheimer E, Love JC, et al. Implantation of balloon-expandable stents for coarctation of the aorta: implantation data and short-term results. Cathet Cardiovasc Diagn 1996;39:36-42.

14 Pedulla DM, Grifka RG, Mullins CE, et al. Endovascular stent implantation for severe recoarctation of the aorta: case report with angiographic and 18-month clinical follow-up. Cathet Cardiovasc Diagn 1997;40:311-14.

15 Thanopoulos BV, Triposkiadis F, Margetakis A, et al. Long segment coarctation of the thoracic aorta: treatment with multiple balloon-expandable stent implantation. Am Heart 7 1997; 133:470-3.

16 Ledesma M, Diaz y Diaz E, Alva Espinoza C, et al. Stents in aortic coarctation. Immediate results. Arch Inst Cardiol Mex 1997;67:399-404.

17 Hakim F, Hawelleh AA, Goussous Y, et al. Simultaneous stent implantation for coarctation of the aorta and closure of patent ductus arteriosus using the Amplatzer duct occluder. Catheter Cardiovasc Intervent 1999;47:36-8.

18 Tynan M, Finley JP, Fontes V, et al. Balloon angioplasty for the treatment of native coarctation: results of valvuloplasty and angioplasty of congenital registry. $A m \neq$ Cardiol 1990;65:790-2.

19 Syamasundar Rao P. Aortic rupture after balloon angioplasty of aortic coarctation. Am Heart f 1993;125: 1205-6.

20 Steingerg C, Weinstock DJ, Gold JP, et al. Measurements of central blood vessels in infants and children: normal values. Catheter Cardiovasc Intervent 1992;27:197-201.

\section{IMAGES IN CARDIOLOGY}

\section{Adenosine testing for accessory pathways: not as simple as it seems}

Not all patients who suffer from atrioventricular reciprocating tachycardia have a delta wave on their resting ECG. Concealed pathways only conduct retrogradely, while in latent pre-excitation the accessory pathway has a net conduction time to the ventricle (that is, intraatrial conduction plus AP conduction times) greater than the net conduction time via the atrioventricular (AV) node. Latent conduction may be unmasked by blocking AV nodal conduction with adenosine ("adenosine testing") but a third possibility, which can also be unmasked by this technique, is intermittent pre-excitation.

A 26 year old man with intermittent palpitations and a normal resting ECG received $18 \mathrm{mg}$ of adenosine. Initially (1) there is progressive lengthening of the PR interval (vertical arrow $=\mathrm{P}$ waves), and the sixth $\mathrm{P}$ wave is an echo beat (oblique arrow). Theaccessory pathway then (2) begins to conduct (the PR interval is short, proving intermittent rather than latent conduction), but only alternate beats are transmitted because of a long refractory period. The very broad QRS suggests that the AV node is completely blocked at this stage. Accessory pathway refractory period shortens (3) (either because of enhanced sympathetic tone or another direct effect of adenosine), and AV nodal conduction recovers (open arrow $=$ fusion beat). Finally (4), 1:1 AV conduction returns and the typical ECG appearances of the Wolff-ParkinsonWhite syndrome is seen. Accessory pathway conduction disappeared soon thereafter.

JOHAN E P WAKTARE JOHN FORAN DAVID E WARD

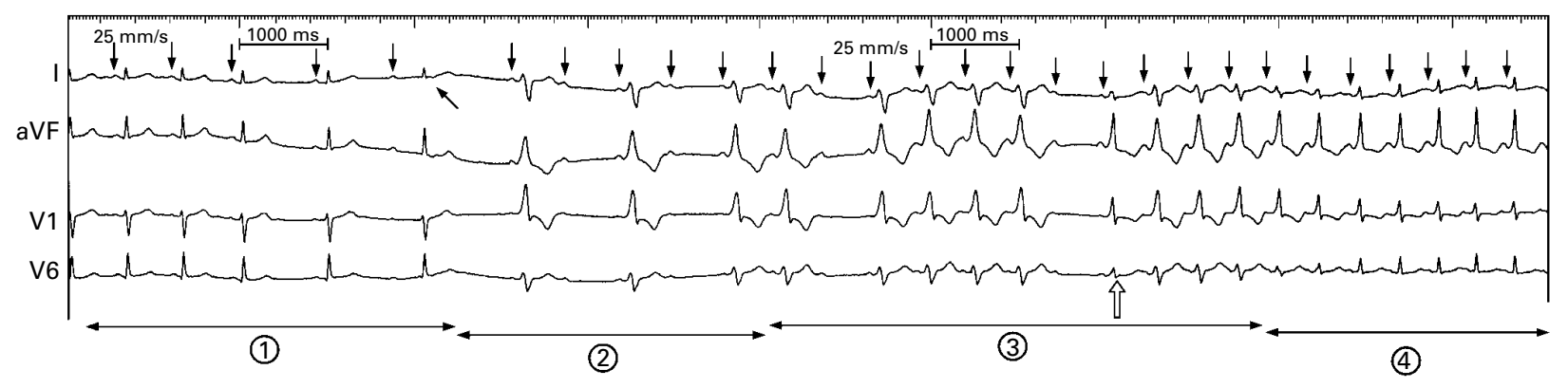

